\title{
Desenvolvimento morfológico de Lotus spp. de diferentes hábitos de crescimento $^{1}$
}

\author{
Rita Poles Maroso², Simone Meredith Scheffer-Basso ${ }^{3}$ \\ 1 Parte da dissertação da primeira autora apresentada ao curso de Pós-Graduação em Agronomia, Área de Produção Vegetal, Universidade \\ de Passo Fundo. \\ 2 Bióloga, Mestre em Agronomia (Produção Vegetal). \\ 3 Universidade de Passo Fundo. Bolsista CNPq.
}

RESUMO - Este trabalho foi realizado com o objetivo de comparar cultivares de Lotus corniculatus L. (cv. São Gabriel, cv. ARS2620) e L. uliginosus Schkuhr (cv. Maku) por meio da análise do desenvolvimento morfológico. As plantas foram cultivadas em vasos, colhidas aos 90,120, 150, 180 e 210 dias após a semeadura e avaliadas por medidas lineares e de peso, volume, área e contagem. Os dados foram submetidos à análise de regressão em função dos dias de crescimento. Os cultivares apresentaram a mesma tendência temporal quanto à estatura, ao volume radical e à massa seca (MS) aérea, mas diferiram quanto à grandeza das alterações. O acúmulo de MS (g/planta) foi superior nos cultivares Maku $(15,0)$ e S. Gabriel $(14,0)$ em relação ao cultivar ARS2620 (11,0). Os cultivares S. Gabriel, Maku e ARS2620 diferiram quanto ao diâmetro da planta (96,7; 80,7; $68,5 \mathrm{~cm})$, ao diâmetro da coroa $(6,5 ; 15,7 ; 8,1 \mathrm{~mm})$, ao comprimento da massa radical $(37,8 ; 29,2 ; 40,4 \mathrm{~cm})$ e ao número de hastes da coroa (37,8; 29,2 e 40,4). O sistema subterrâneo foi mais vigoroso no cultivar Maku, que produziu mais MS de sóboles $(16,3)$ em relação aos cultivares ARS2620 (4,7) e São Gabriel $(2,0)$, mostrando ser potencialmente mais persistente em condições de pastejo.

Palavras-chave: análise de crescimento, Lotus corniculatus, L. uliginosus, sóboles

\section{Morphological development of Lotus spp. with different growth habit}

ABSTRACT - This work aimed to compare cultivars of Lotus corniculatus L. (cv. São Gabriel, cv. ARS2620) and L. uliginosus Schkuhr (cv. Maku) through the morphological development analysis. The plants were cultivated in pots and they were harvested at $90,120,150,180$, and 210 days after seeding being evaluated by linear, weight, volume, area, and count measurements. Data were submitted to regression analysis as a function of growth days. Cultivars had the same temporal trend for height, root volume, and shoot dry matter (DM), but differed in terms of the magnitude. The DM accumulation (g/plant) was greater for the cvs. Maku (15.0) and S. Gabriel (14.0) in relation to cv. ARS2620 (11.0). The cvs. S. Gabriel, Maku, and ARS2620 differed respectively for plant diameter: 96.7, 80.7, and $68.5 \mathrm{~cm}$; crown diameter: 6.5, 15.7, and $8.1 \mathrm{~mm}$; root mass extension: 37.8, 29.2, and $40.4 \mathrm{~cm}$; crown stem number: 37.8, 29.2, and 40.4. The underground system was more vigorous in the cv. Maku, which produced more soboles MS (16.3) in relation to cvs. ARS2620 (4.7) and São Gabriel (2.0), showing potentially more persistence under grazing condition.

Key Words: growth analysis, Lotus corniculatus, L. uliginosus, sobole

\section{Introdução}

O cornichão (Lotus corniculatus L.) é uma leguminosa forrageira de grande importância em diversos países, especialmente o Uruguai, onde é utilizada no melhoramento de extensas áreas de pastagens naturais. É uma espécie perene que pode persistir na pastagem por meio da sobrevivência da planta-mãe e por ressemeadura natural. A durabilidade é extremamente dependente do vigor e da sanidade da coroa, que se localiza entre a raiz e o caule, delimitada pelo nó cotiledonar (Marques-Ortiz et al., 1996). No Brasil, o único cultivar disponível comercialmente é o cv. São Gabriel, resultante de trabalhos realizados na Estação Experimental de São Gabriel, Rio Grande do Sul, entre 1955 e 1965, quando seu cultivo se expandiu para outros países da América do Sul (Paim, 1988). Apesar da boa produtividade e do valor nutritivo, seu hábito de crescimento ereto não condiz com os tipos morfológicos de plantas ideais para pastagens (Oliveira et al., 1990), tendo em vista sua pouca persistência ao pastejo. Esse fator é provavelmente a principal causa da pouca expansão dessa leguminosa no Sul do Brasil, onde o sucesso de sua introdução nas pastagens naturais (aproxi- 
madamente 10 milhões de hectares) poderia auxiliar no melhoramento dos índices zootécnicos.

A busca pela melhoria da persistência de leguminosas forrageiras é global e difícil, pois seu uso está vinculado à consorciação com gramíneas, sabidamente mais agressivas e rústicas. Com o cornichão não tem sido diferente. No entanto, com a descoberta de tipos sobolíferos no Marrocos, houve chance de se aumentar a persistência da espécie (Li \& Beuselinck, 1996) por meio de cruzamentos com o tipo comum. Foram iniciados, em 1989, nos Estados Unidos, trabalhos voltados à incorporação dessa característica em cultivares comerciais de cornichão, que culminaram com o lançamento do cultivar ARS2620, caracterizado pela presença de rizomas (Beuselinck \& Steiner, 1996). Esse cultivar, por propagar-se vegetativamente, é menos dependente de suas reservas (Wen et al., 2002); seu hábito prostrado condiz com plantas aptas ao pastejo, com grande quantidade de gemas próximas ao solo.

Os estudos do sistema subterrâneo de populações do cultivar São Gabriel e sua comparação aos tipos marroquinos comprovaram a existência de caules subterrâneos também no cultivar brasileiro (Soster et al., 2004a), o que sugeriu inicialmente que essa característica do cornichão não seria exclusiva ao cultivar marroquino e que estudos de ontogênese e anatomia seriam importantes para a elucidação dessas estruturas. Estudos anatômicos confirmaram a similaridade entre os caules subterrâneos do cultivar São Gabriel e os caules subterrâneos nos cultivares americanos, obtidos do cruzamento do cornichão comum com os cornichões classificados como rizomatosos (Maroso et al., 2004). Com base nos critérios morfológicos adotados por Apezzato da Glória (2003) esses caules subterrâneos são do tipo sóbole, que difere do rizoma por não se originar da plúmula, não emitir caules aéreos e não possuir nós e entrenós tão evidentes.

L. uliginosus Schkuhr, denominado vulgarmente cornichão-dos-banhados e cornichão-dos-campos úmidos, também é descrito como rizomatoso. Os rizomas são importantes para o estabelecimento das plantas quanto à propagação lateral, principalmente após o terceiro ano de estabelecimento, quando a energia necessária para a manutenção e o crescimento da planta provém das fontes de armazenamento dessas estruturas (Wedderburn \& Gwynne, 1981). Além disso, a espécie possui também a vantagem de possuir hábito decumbente, o que favorece a expansão lateral da planta.

Com intuito de colaborar com estudos de melhoramento genético de cornichão, realizou-se este estudo visando comparar três cultivares de Lotus sp. de diferentes hábitos por meio da descrição quantitativa de seu crescimento.

\section{Material e Métodos}

O experimento foi conduzido na Universidade de Passo Fundo, região do Planalto Médio do Rio Grande do Sul, com coordenadas de $28^{\circ} 15^{\prime} \mathrm{S}, 52^{\circ} 24^{\prime \prime} \mathrm{W}$ e a $687 \mathrm{~m}$ de altitude no período de maio a dezembro de 2004 . O clima é temperado subtropical úmido (Cfa), com temperatura média anual de $22^{\circ} \mathrm{C}$ (Moreno, 1961) (Figura 1).

O ensaio constou da avaliação de dois cultivares de cornichão (S. Gabriel, brasileiro; e ARS2620, americano) e um de cornichão-dos-banhados (Maku, neozelandês), colhidos integralmente em cinco idades: 90, 120, 150, 180 e 210 dias de crescimento. O delineamento experimental foi em blocos casualizados, com três repetições. O cultivo das plantas foi feito em ambiente semiprotegido, composto de um telado com cobertura impermeável transparente e telas plásticas do tipo clarite como proteção lateral. As unidades experimentais constaram de vasos de plástico com capacidade para $5 \mathrm{~kg}$ de solo seco, perfurados na base e com pequena camada de brita no fundo. $O$ substrato constou de uma mistura de solo obtido de lavoura, dois tipos de cama sobreposta de suíno, à base de maravalha e de casca de arroz, e areia, na proporção de 60:30:7:3. A análise químicofísica desse substrato comprovou as seguintes características: $\mathrm{pH}$ - 5,3; P - 51 mg/L; K - $201 \mathrm{mg} / \mathrm{L}$; argila - 36\%; $\mathrm{MO}$ - 6,1\%; $\mathrm{Al}-0,0 \mathrm{cmol}_{\mathrm{C}} / \mathrm{dm}^{3} ; \mathrm{Ca}-6,7 \mathrm{cmol}_{\mathrm{c}} / \mathrm{dm}^{3}$; $\mathrm{Mg}-6,4 \mathrm{cmol}_{\mathrm{c}} / \mathrm{dm}^{3} ; \mathrm{H}+\mathrm{Al}-3,9 \mathrm{cmol}_{\mathrm{c}} / \mathrm{dm}^{3}$; e CTC: $17,5 \mathrm{cmol}_{\mathrm{C}} / \mathrm{dm}^{3}$. Não houve necessidade de adição de nenhum tipo de fertilizante, pois as características do substrato estavam de acordo com as exigências das espécies em estudo. Em maio de 2004, procedeu-se à semeadura e, após a emergência, realizou-se o desbaste deixando-se uma planta por vaso. A inoculação foi realizada aos 60 e 130

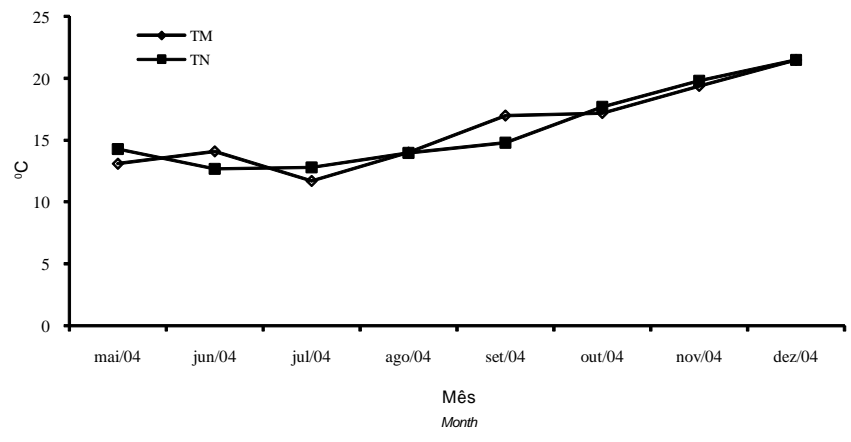

Figura 1 - Temperaturas médias (TP = período; TN = normais) $\mathrm{e}$ precipitação mensal ( $\mathrm{PP}=$ período; $\mathrm{PN}=$ normais $)$. Fonte: www.cnpt.embrapa.br.

Figure 1 - Average temperatures (TP = period; $T N=$ normal) and monthly rainfall $(P P=$ period; $P N=$ normal $)$. Source: www.cnpt.embrapa.br. 
dias com uma solução de Rhizobium lotii a 2 g/L, na quantidade de $250 \mathrm{~mL} / \mathrm{vaso}$, mediante rega. Em razão de um leve amarelecimento das plantas, aos 90 e 180 dias realizou-se aplicação de uma solução de uréia a 3\%, na quantidade de $250 \mathrm{~mL} /$ vaso. As plantas foram mantidas sem restrição hídrica.

As colheitas foram feitas mensalmente, de forma simultânea, entre agosto e dezembro para os três cultivares. As avaliações constaram de medidas lineares, de contagem, de superfície, de peso e volume (Benincasa, 2003) e, a partir dos dados de pesagem, calculou-se a relação folha:caule. No momento da colheita, as plantas foram avaliadas quanto à estatura, respeitando-se o caimento natural da planta. $\mathrm{O}$ diâmetro neste estudo foi convencionado como a distância entre as extremidades das duas hastes mais longas, distendidas e opostas. Posteriormente, as plantas foram retiradas dos vasos, lavadas em água corrente e levadas ao laboratório, onde a parte subterrânea foi separada em raízes e sóboles e a parte aérea, em hastes e folhas. Nesse material, foram avaliados o diâmetro da coroa, o comprimento da raiz mais longa, o comprimento da haste mais longa e dos entrenós dessa haste, a área foliar, o número de hastes axilares e da coroa, o volume de raízes e o acúmulo de massa seca (MS) de folhas, hastes aéreas, sóboles e raízes. Para obtenção da MS, esses componentes foram secos em estufa a $60^{\circ} \mathrm{C}$. Os resultados foram submetidos à análise de regressão em função dos dias de crescimento após semeadura, em modelo de parcela subdividida no tempo considerando as plantas a parcela principal e as idades, as subparcelas.

\section{Resultados e Discussão}

A análise da variância evidenciou efeito de cultivar para estatura, volume de raízes, MS de hastes e da parte aérea. Para essas variáveis, acrescidas do número e da MS de hastes, da MS total, do comprimento de entrenós, da relação folha:caule, área foliar, houve efeito de idade. Apenas para diâmetro de planta e coroa, extensão da massa radical, número de hastes da coroa e MS foliar, houve interação $(\mathrm{P}<0,05)$ cultivar $\times$ idade.

Ao final da fase de estabelecimento (90 dias), os cultivares tiveram estatura média de $4,1 \mathrm{~cm}$ e suas hastes se caracterizaram por entrenós curtos $(1,5 \mathrm{~cm})$. A partir dessa idade, verificou-se aumento quadrático da estatura e linear do comprimento dos entrenós. Aos 210 dias, as plantas não florescidas estavam com $21 \mathrm{~cm}$ de estatura e entrenós de 3,7 cm (Figura 2). Na média das idades, as estaturas dos cultivares S. Gabriel (18,4 cm) e Maku (16,1 cm) foram superiores $(\mathrm{P}<0,05)$ à do cultivar ARS2620 $(9,1 \mathrm{~cm})$. Esse resultado foi similar ao obtido por Soster et al. (2004a), que verificaram estaturas entre 14,3 e 30,2 cm (S. Gabriel) e
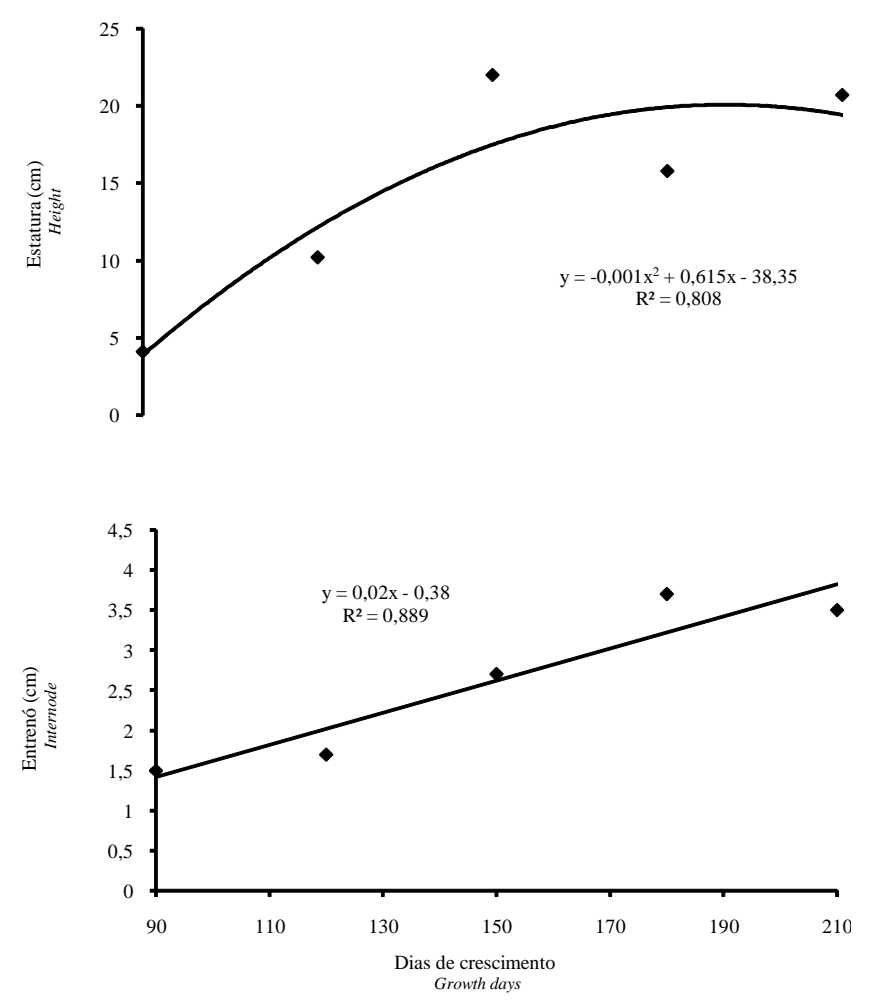

Figura 2 - Estatura média das plantas e comprimento médio dos entrenós de Lotus sp., cultivares ARS2620, Maku e São Gabriel, no período de crescimento.

Figure 2 - Average plant height and internode length of Lotus sp. (mean of cvs. ARS2620, Maku and São Gabriel) as a function of growth days after the seeding.

7,5 cm no cultivar ARS2620. No campo, esses autores observaram altura de 26 a $28 \mathrm{~cm}$ para S. Gabriel e $12 \mathrm{~cm}$ para ARS2620. Scheffer-Basso et al. (2001b), em casa de vegetação, registraram altura entre 17,5 e 31 cm no cultivar S. Gabriel.

A estatura é um atributo estreitamente relacionado ao hábito de crescimento. Caroso et al. (1981), em cornichão, observaram que plantas com hábito mais ereto foram menos persistentes, principalmente quando submetidas a cortes ou pastejo. No entanto, neste trabalho as plantas não foram avaliadas sob corte, como esses autores o fizeram. Assim, o hábito ereto do cultivar São Gabriel se manifestou apenas nas hastes centrais, uma vez que as hastes laterais tenderam à decumbência, em virtude do crescimento ininterrupto. A busca por plantas forrageiras prostradas está relacionada ao fato de que, após o pastejo, permanece maior número de gemas ao nível do solo em relação às mais eretas (Nelson \& Moser, 1994). No entanto, mesmo em plantas mais prostradas, cujos caules são ascendentes por ocasião do florescimento, ocorrem alongamento dos entrenós e elevação do dossel (Formoso, 1993; Soster et al., 2004a) e, conseqüentemente, o pastejo remove os pontos de crescimento mais elevados, atrasando a rebrota. Neste trabalho, 
apesar de não ter ocorrido florescimento, os entrenós também alongaram, alcançando $4 \mathrm{~cm}$ (Figura 2). A ausência de florescimento pode ser atribuída, em parte, às condições de cultivo, especialmente à ausência de restrição hídrica, o que estimulou a constante emissão de hastes e folhas. Além disso, a própria idade das plantas, que não excedeu 210 dias, pode ter sido insuficiente para diferenciação floral. Em casa de vegetação, Soster et al. (2004a) observaram o florescimento de genótipos de cornichão entre 170 e 270 dias de idade e notaram que o cultivar ARS2620 foi mais tardio e floresceu entre 231 e 247 dias. Monteiro \& Paim (1982) verificaram no campo florescimento do cultivar Maku apenas aos 223 dias após o plantio.

A pequena estatura média das plantas $(4,1 \mathrm{~cm})$ aos 90 dias também reforçou o comportamento observado no cornichão, ou seja, seu lento crescimento inicial, relacionado, em parte, ao baixo vigor de suas sementes, o que dificulta seu uso na formação de pastagens (Shibles \& MacDonald, 1964; Cooper, 1966; Beuselinck \& McGraw, 1983), em especial sob condições de competição com outras plantas na comunidade vegetal. No entanto, após esse período crítico, a espécie é capaz de elevadas produções. Em consorciação com festuca (Festuca arundinacea Schreb.), Scheffer-Basso et al. (2002a) obtiveram boa produção de MS $(3.500 \mathrm{~kg} / \mathrm{ha})$ no cultivar S. Gabriel no ano do estabelecimento.

O desenvolvimento das plantas forrageiras perenes, em geral, é lento na fase inicial, mas, à medida que a parte aérea se expande, as taxas de crescimento aumentam. Neste estudo, aos 90 dias as plantas apresentavam aproximadamente 13 hastes (Figura 3) e aumentos lineares aos 210 dias de idade (em torno de 230 hastes/planta), comprovando o vigor e a dinâmica desse processo, que refletiram em acúmulo de MS. Na média das idades, os cultivares S. Gabriel (13,9 g de MS/planta) e Maku (14,9 g de MS/ planta) foram superiores $(\mathrm{P}<0,05)$ ao cultivar ARS2620 (10,9 g de MS/planta), revelando diferenças em dimensão.

As formas de crescimento das plantas são características que devem ser consideradas quando se comparam suas produções (Steiner \& Garcia de los Santos, 2001; Soster et al., 2004a). Considerando que o cultivar São Gabriel é ereto, o ARS2620 é prostrado e o Maku é decumbente, os resultados confirmaram o que se esperava, ou seja, a menor produção do cultivar ARS2620. A produção de novas hastes e o aumento dos sítios meristemáticos promoveram aumento da área foliar, como observaram Nelson \& Smith (1968), em cornichão e alfafa (Medicago sativa L.). Aos 210 dias de crescimento, as plantas apresentaram área foliar de $4.500 \mathrm{~cm}^{2}$ e produção de MS foliar de $20 \mathrm{~g} /$ planta (Figura 4).
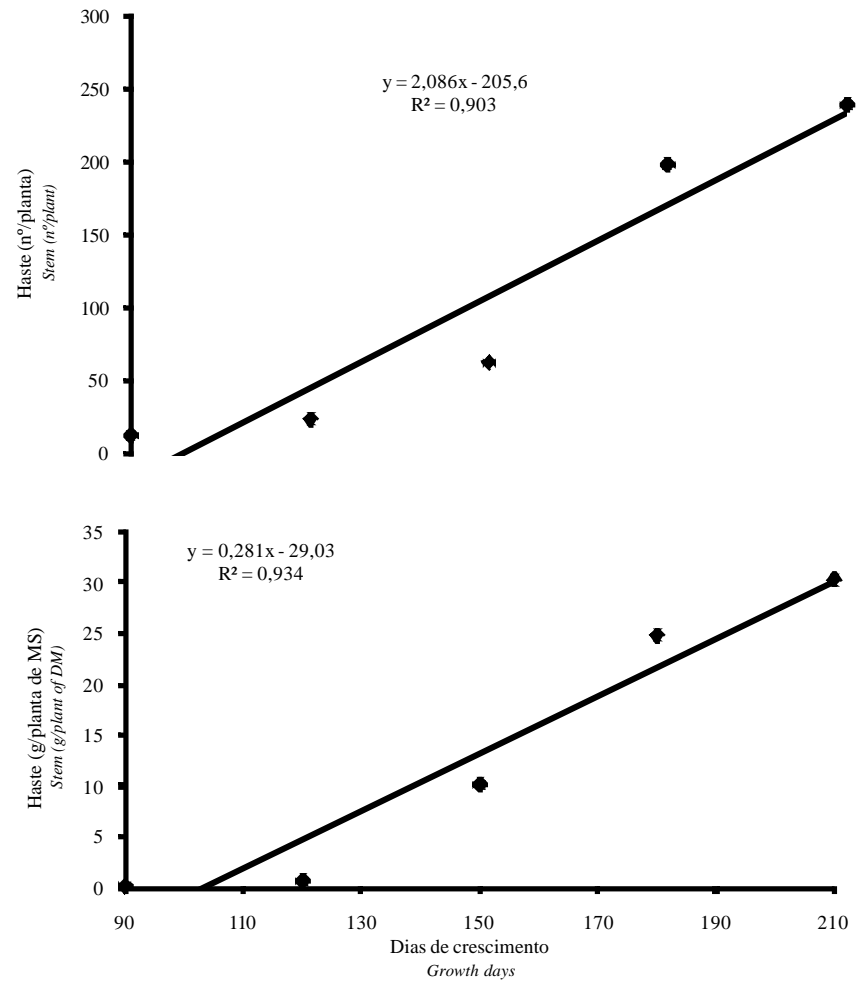

Figura 3 - Número e acúmulo de MS de hastes de Lotus sp. (média dos cultivares ARS2620, Maku e São Gabriel) no período de crescimento.

Figure 3 - Number of stems and stem dry matter accumulation of Lotus sp. (mean of cvs. ARS2620, Maku and São Gabriel) as a function of growth days after the seeding. Passo Fundo, RS, 2004.

O que mais importa para o pastejo é a capacidade da planta em produzir folhas, uma vez que são preferencialmente selecionadas pelos animais, em decorrência do maior valor nutritivo em relação aos caules.É indiscutível a importância da área foliar para o desenvolvimento e a produção de forrageiras (Brougham, 1956; Scheffer-Basso et al., 2002b). Com o final do inverno e o início da primavera, a partir dos 120 dias de crescimento, as plantas tiveram expressivo aumento da produção de MS e aos 210 dias de idade estavam com 50 e $70 \mathrm{~g} /$ planta na parte aérea e no total (Figura 5). Na média das idades, os cultivares $\mathrm{S}$. Gabriel (24,6 g de MS/planta) e Maku (24,4 g de MS/planta) foram superiores $(\mathrm{P}<0,05)$ ao ARS2620 (19,6 g de MS/ planta) quanto à parte aérea, confirmando a relação com seus diferentes hábitos e tamanhos.

A relação folha:caule reduziu linearmente com a idade das plantas $\left(\hat{y}=-0,0123 x+3,07 ; R^{2}=0,86\right)$ de 2,0 (90 dias) para 0,7 (210 dias)e não diferiu entre os cultivares. Apesar da acentuada redução na relação folha:caule, essa espécie, em razão de seu hábito indeterminado, consegue manter sua forragem com elevado valor nutritivo, pois mesmo em 
florescimento continua emitindo hastes vegetativas, o que permite que nessa espécie possam ser aplicadas técnicas de manejo como o diferimento e o atraso na colheita(Beuselinck et al., 1984).

O sistema subterrâneo dos cultivares foi formado pela raiz primária e suas ramificações, finas e em grande quantidade (raízes fibrosas), bem como pelos sóboles, que foram
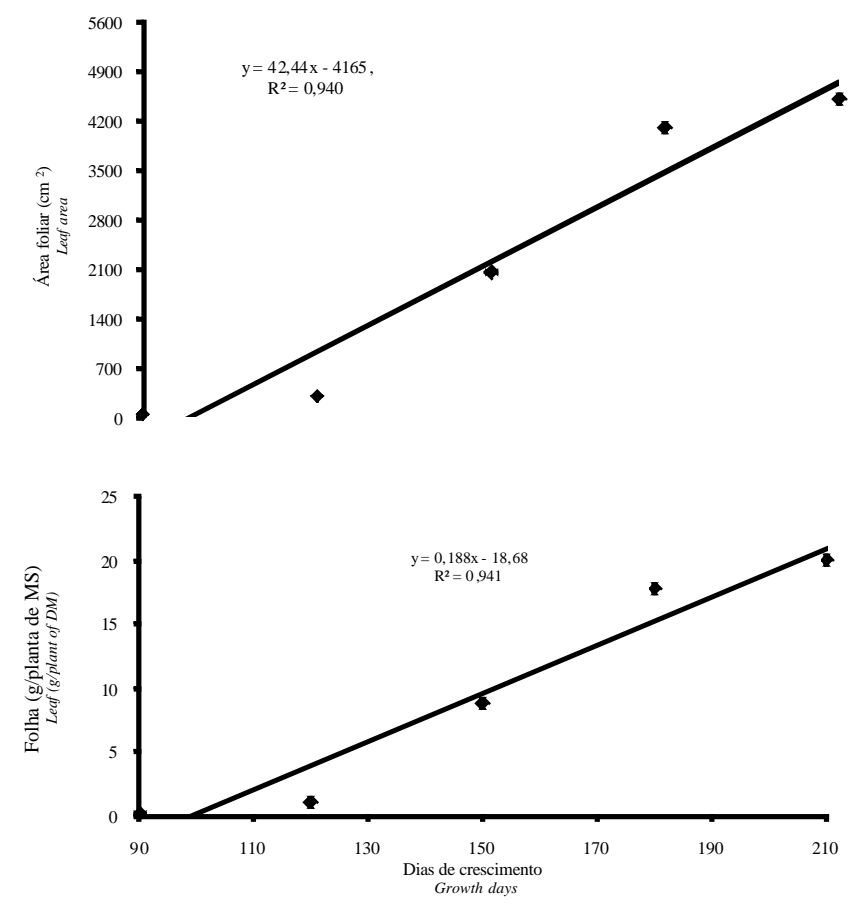

Figura 4 - Área foliar e acúmulo de MS foliar de Lotussp. (média dos cultivares ARS2620, Maku e São Gabriel) durante o crescimento após a semeadura.

Figure 4 - Leaf area and leaf DM accumulation of Lotussp. (mean of cvs. ARS2620, Maku and São Gabriel) as a function growth days after the seeding. Passo Fundo, RS, 2004.

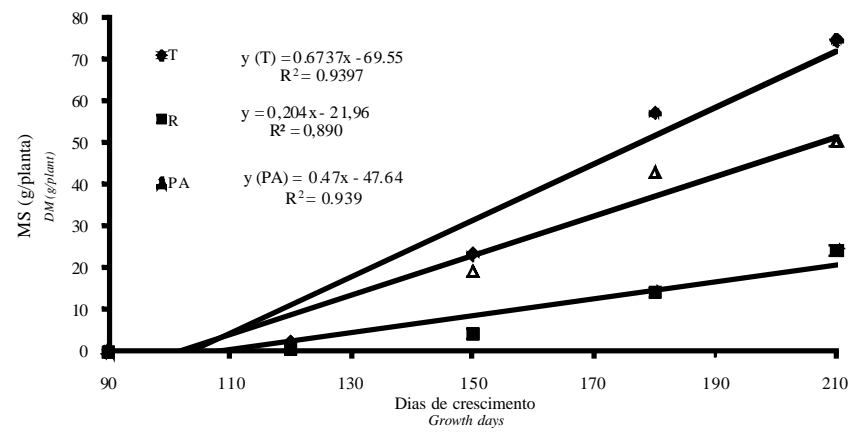

Figura 5 - Acúmulo de MS de raízes (R), parte aérea (PA) e total ( $T$ = R+PA) de Lotus sp. (média dos cultivares ARS2620, Maku e São Gabriel) no período de crescimento.

Figure 5 - DM accumulation of roots $(R)$, shoot $(P A)$, and total $(T=R+P A)$ of Lotus sp. (mean of cvs. ARS2620, Maku and São Gabriel) as function of growth days after the seeding. Passo Fundo, RS, 2004. quantificados na última colheita, quando estavam presentes nos três cultivares. A massa radical aumentou linearmente em comprimento, especialmente a partir do $150^{\circ}$ dia, quando os dois cultivares de cornichão se destacaram positivamente do cornichão-dos-banhados (Figura 6), o que também ocorreu com o volume (Figura 7), que chegou ao final dos $210 \mathrm{dias} \operatorname{com} 100 \mathrm{~cm}^{3} /$ planta (dados não apresentados), de modo que, na média das idades, os cultivares São Gabriel e Maku superaram $(\mathrm{P}<0,05)$ o cultivar ARS2620.

Monteiro \& Paim (1982) referiram-se ao cornichão como uma espécie de raiz profunda, o que lhe confere resistência a períodos de estiagem, diferentemente do cultivar Maku, que possui raízes curtas. Neste estudo, esse cultivar apresentou também um sistema subterrâneo mais superficial, com raízes mais curtas e bifurcadas e sóboles densamente enraizados, características de plantas tolerantes a solos ácidos e de baixa fertilidade, conforme descrito por Wedderburn \& Gwynne (1981), e de espécies adaptadas a solos pobres em fósforo e com alto teor de umidade (Lowther, 1980; Davis, 1981). As diferenças entre o comprimento e a distribuição das raízes explicam a maior persistência de Lotus, em comparação à alfafa, a solos rasos e mal drenados (Seaney \& Henson, 1970), característica importante, especialmente na comparação de genótipos.

O cultivar Maku se destacou pela maior alocação de MS em sóboles (16,3 g/planta) em relação aos cultivares ARS2620 $(4,7 \mathrm{~g})$ e S. Gabriel (2,0 g), nos quais o aparecimento desses caules ocorreu somente a partir do 180 o dia e, ao contrário do cultivar Maku, não apresentaram enraizamento nesse período. Os sóboles originaram-se da coroa, apresentaram crescimento lateral, ausência de catáfilos e, após um período de crescimento, emergiram do solo, tornando-se clorofilados e desenvolvendo hastes e folhas. Essas características botânicas estão de acordo com os critérios de Appezatto da

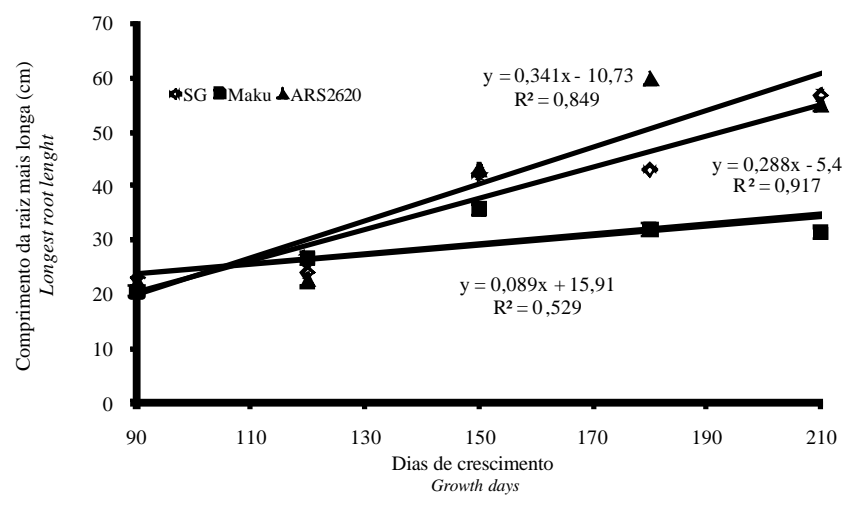

Figura 6 - Comprimento da raiz mais longa de cultivares de Lotus sp. no período de crescimento.

Figure 6 - Root length of Lotus sp. cultivars as a function of the growth days after the seeding. Passo Fundo, RS, 2004. 


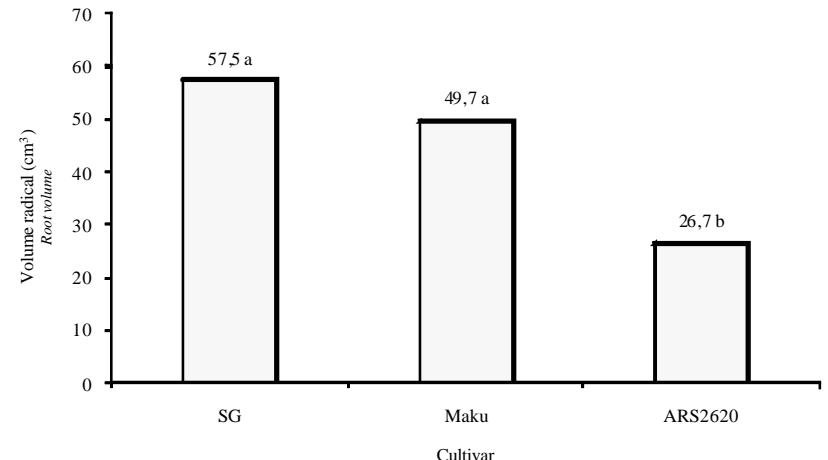

Figura 7 - Volume radical de cultivares de Lotus sp.

Figure 7 - Root volume of Lotus sp. cultivars.

Glória (2003) para enquadrar estes caules como sóboles, indicando, portanto, que não se tratam de rizomas como descrito por Li \& Beuselinck (1996).

Os cultivares diferiram quanto ao diâmetro de planta e coroa (Figura 8). O cultivar ARS2620 teve menor diâmetro de planta, em virtude de seu menor tamanho e hábito mais prostrado, o que está de acordo com os resultados descritos por Soster et al. (2004b). No cultivar S. Gabriel, o maior diâmetro foi ocasionado por suas longas hastes. Na Inglaterra, segundo Bonnemaison \& Jones (1986), o diâmetro da planta de cornichão é uma característica que contribui para diferenciar os tipos nativos de cornichão dos exóticos; os primeiros são menores e normalmente mais persistentes.

O cultivar Maku se destacou pelo tamanho de coroa, $124 \%$ maior que do cultivar S. Gabriel, comprovando maior potencial para emissão de hastes basilares. Considerando a importância dessa estrutura como fonte de sítios meristemáticos e local de reservas orgânicas, esse resultado sugere que, nos programas de melhoramento do cultivar S. Gabriel, o aumento do tamanho da coroa deveria ser um dos principais objetivos na seleção de tipos com aptidão para pastejo. A alta produtividade e a persistência de leguminosas forrageiras podem estar associadas à morfologia dessa estrutura, indicando maior ou menor vulnerabilidade às injúrias ao pastejo (Marques-Ortiz et al., 1996). Wasson \& Barnet (1971) verificaram em cornichão relação positiva entre a porção da coroa mantida abaixo da superfície do solo e a emissão de novas hastes no período pós-inverno.

Durante o período de estabelecimento (90 dias), o desenvolvimento da coroa foi pequeno, assim como o número de hastes originadas da coroa (Figura 9). No entanto, com o aumento das temperaturas, principalmente a partir do 120 o dia (Figura 1), observou-se maior ritmo nesse proces so, especialmente no cultivar ARS2620. Smith (1962) também
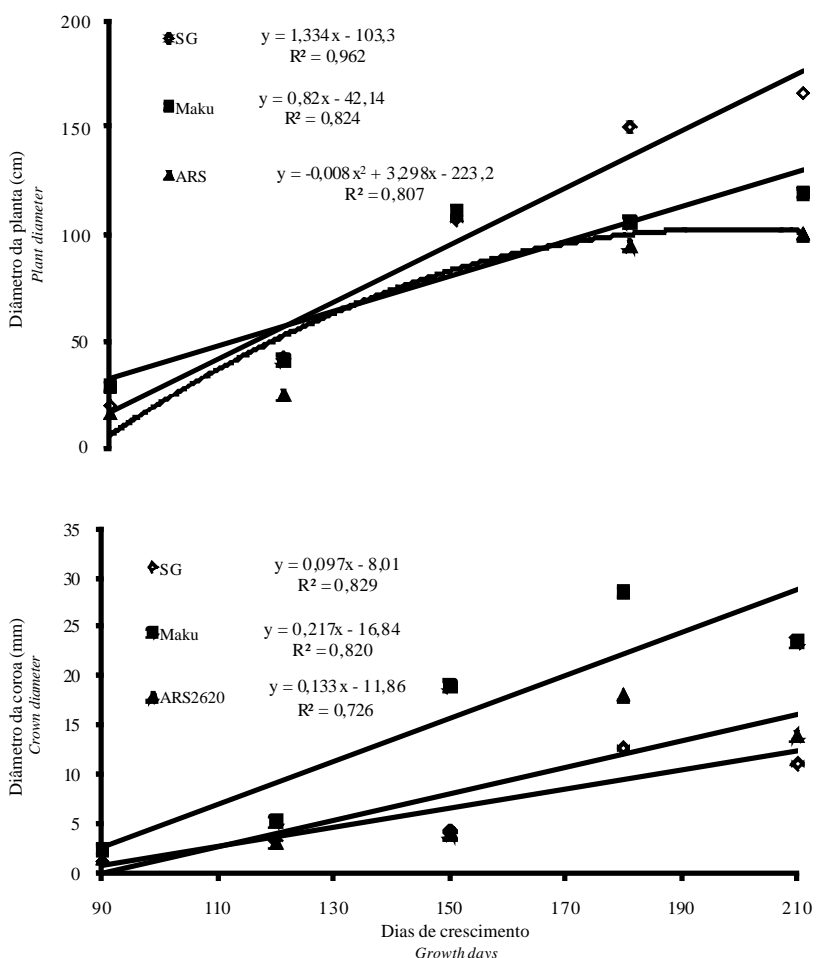

Figura 8 - Diâmetro das plantas e da coroa de Lotus sp. no período de crescimento.

Figure 8 - Plant and crown diameter of Lotus sp. cultivars as a function of growth days after the seeding. Passo Fundo, RS, 2004.

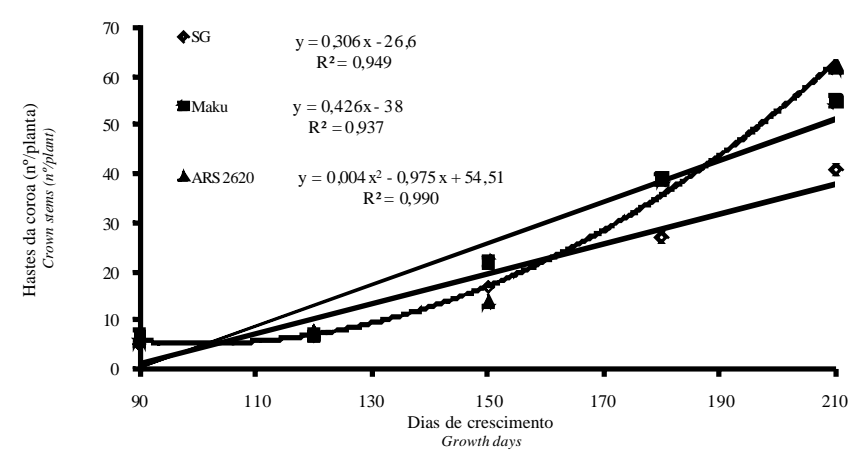

Figura 9 - Número de hastes da coroa de cultivares de Lotussp. no período de crescimento.

Figure 9 - Crown stems number of Lotus sp. cultivars as function of growth days after the seeding. Passo Fundo, RS, 2004

observou, em cornichão, que a emissão de hastes da coroa ocorreu no início da primavera.

$\mathrm{O}$ aumento foi constante e linear para os cultivares Maku e S. Gabriel, que atingiram aos 210 dias 41 e 52 hastes da coroa, respectivamente. No cultivar ARS2620, a tendência foi de maiores aumentos a partir do $150 \mathrm{O}$ dia de idade, $\mathrm{o}$ 
que resultou em 62 hastes aos 210 dias, expressão marcante de sua maior ramificação em nível basilar. Geralmente, em plantas de hábito mais prostrado, como os cultivares Maku e ARS2620, há maior emissão de gemas basilares. Em espécies mais eretas, como cv. S. Gabriel, verifica-se maior proporção de gemas axilares (Araújo \& Jacques, 1974; Nelson \& Smith, 1968; Scheffer-Basso et al., 2000).

\section{Conclusões}

Os cultivares de Lotus spp. estudados possuem o mesmo padrão temporal de desenvolvimento quanto à es tatura, ao volume radical e à massa seca área, no entanto, diferem quanto à grandeza das alterações, de modo que o maior potencial de produção de massa seca ocorre nos cultivares Maku e São Gabriel.

Os cultivares diferem em nível temporal e de grandeza quanto ao diâmetro das plantas e da coroa, ao comprimento do sistema radical e ao número de hastes da coroa; seu sistema subterrâneo é do tipo difuso, formado por raízes e sóboles, de modo que o cultivar Maku se sobressai pelo maior vigor, indicando diferenças interespecíficas.

\section{Agradecimento}

Ao Professor Miguel Dall'Agnol, da Universidade Federal do Rio Grande do Sul, pelo envio das sementes, e à Professora Dileta Cecchetti, da Universidade de Passo Fundo, pelo auxílio na análise estatística.

\section{Literatura Citada}

APPEZZATO DA GLÓRIA, B. Morfologia de sistemas subterrâneos : história e evolução do conhecimento no Brasil. Ribeirão Preto: Editora e Arte, 2003. s.p.

ARAÚJO, J.C.; JACQUES, A.V.A. Características morfológicas e produção de matéria seca de cornichão (Lotus corniculatus L.) colhido em diferentes estádios de crescimento e a duas alturas corte. Revista Brasileira de Zootecnia, v.3, p.138$147,1974$.

BENINCASA, M.M.P. Análise de crescimento de plantas. Jaboticabal: Funep, 2003. 41p.

BEUSELINCK, P.R.; McGRAW, R.L. Seedling vigor of three Lotus species. Crop Science, v.23, p.390-391, 1983.

BEUSELINCK, P.R.; PETERS, E.J.; McGRAW, R.L. Cultivar and management effects on stand persistence of birdsfoot trefoil. Agronomy Journal, v.76, p.490-492, 1984.

BEUSELINCK, P.R.; LI, B.; STEINER, J.J. Rhizomatous Lotus corniculatus L.; I. Taxonomic and cytological study. Crop Science, v.36, p.179-185, 1996.

BONNEMAISON, F.; JONES, D.A. Variation in alien Lotus corniculatus L. 1. Morphological differences between alien and native British plants. The Genetical of Great Britain, v.56, p.129-138, 1986 .

BROUGHAM, R.W. Effect of intensity of defoliation on regrowth of pasture. Australian Journal Agricultural Research, v.7, p. 377-387, 1956 .
CAROSO, G.F.; PAIM, N.R.; PRATES, E.R. Avaliação da produção e persistência de progênies e cultivares de Lotus corniculatus $\mathrm{L}$. Pesquisa Agropecuária Brasileira, v.16, p.341-346, 1981.

COOPER, C.S. Response of birdsfoot trefoil and alfalfa to various levels of shade. Crop Science, v.6, p.63-66, 1966.

DAVIS, M.R. Growth and nutrition of legumes on a high country yellow-brown earth subsoil. New Zealand Journal of Agricultural Research, v.24, p.324-332, 1981.

FORMOSO, F. Lotus corniculatus. I. Performance forragera y características agronômicas asociadas. Montevideo Instituto Nacional de Investigación Agropecuaria, 1993. 20p.

LI, B.; BEUSELINCK, P.R. Rhizomatous Lotus corniculatus L. II. Morphology and anatomy of rhizomes. Crop Science, v.36, p.407-411, 1996 .

LOWTHER W.L. Establishment and growth of clovers and Lotus on acid soil. New Zealand Journal Experimental Agriculture, v.8, p.131-138, 1980.

MAROSO, R.P.; CARNEIRO, C.M.; BORDIGNON, M.V. et al. Variabilidade morfológica do sistema subterrâneo de Lotus corniculatus L. Agrociência, v.8, p.73-78, 2004.

MARQUES-ORTIZ, J.J.; JOHNSON, L.D.; BARNES, D.K. et al. Crown morphology relationship among alfalfa plant introductions and cultivars. Crop Science, v.36, p.766-770, 1996.

MONTEIRO, I.D.; PAIM, N.R. Teste de progênies de policruzamento de Lotus uliginosus. I. Em mistura com azevém anual. II. Em linhas individuais e com a cultivar Maku. Pesquisa Agropecuária Brasileira, v.17, p.1483-1489, 1982.

MOREnO, J.A. Clima do Rio Grande do Sul. Porto Alegre: Secretaria de Agricultura, 1961. 41p.

NELSON, C.J.; SMITH, D. Growth of birdsfoot trefoil and alfalfa. II. Morphological development and dry matter distribution. Crop Science, v.8, p.21-24, 1968.

NELSON, C.J.; MOSER, L.E. Plant factors affecting forage quality. In: FAHEY, G.C. (Ed.). Forage quality, evaluation, and utilization. Madison: American Society of Agronomy, 1994. p.115-154.

OLIVEIRA, J.C.P.; PAIM, N.R.; FRIES, L.A. Comparação entre três procedimentos na seleção de plantas individuais em Lotus spp. Pesquisa Agropecuária Brasileira, v.25, p.955-961, 1990.

PAIM, N.R. Research on Lotus spp. in Rio Grande do Sul, Southern Brazil. Lotus Newsletter, v.19, p.37-43, 1988.

SCHEFFER-BASSO, S.M.; JACQUES, A.V.A.; DALL'AGNOL, M. et al. Dinâmica da formação de gemas, folhas e hastes de espécies de Adesmia DC. eLotus L. Revista Brasileira de Zootecnia, v.29, p.1961-1968, 2000.

SCHEFFER-BASSO, S.M.; VOSS, M.; JACQUES, A.V.A. Nodulação e fixação biológica de nitrogênio de Adesmia latifolia e Lotus corniculatus em vasos de Leonard. Revista Brasileira de Zootecnia, v.30, p.687-693, 2001b.

SCHEFFER-BASSO, S.M.; VENDRÚSCOLO, M.C.; BARÉA, K. et al. Comportamento de leguminosas (Adesmia, Lotus, Trifolium) em mistura com festuca (Festuca arundinaceae). Revista Brasileira de Zootecnia, v.31, p.2197-2203, 2002a.

SCHEFFER-BASSO, S.M.; JACQUES, A.V.M.; DALL'AGNOL, M. Alocação da biomassa e correlações morfofisiológicas em leguminosas forrageiras com hábitos de crescimento contrastantes. Scientia Agrícola, v.59, p.629-634, 2002 b.

SEANEY, R.R.; HENSON, P.R. Birdsfoot trefoil. Advances in Agronomy, v.22, p.119-157, 1970.

SHIBLES, R.M.; MacDONALD, H.A. Photosynthetic area and rate in relation to seedling vigor of birdsfoot trefoil (Lotus corniculatus L.). Crop Science, v.2, p.299-302, 1964.

SOSTER, M.T.B.; SCHEFFER-BASSO, S.M.; DALL'AGNOL, M. Caracterização morfofisiológica de genótipos de cornichão (Lotus corniculatus L.). Revista Brasileira de Zootecnia, v.33, p.1654-1661, 2004a.

SOSTER, M.T.B.; SCHEFFER-BASSO, S.M.; DALL'AGNOL, M. et al. Caracterização agronômica de genótipos de cornichão 
(Lotus corniculatus L.) Revista Brasileira de Zootecnia, v.33, p.1662-1671, 2004b.

STEINER, J.J.; GARCIA DE LOS SANTOS, G. Adaptative ecology of Lotus corniculatus L. genotypes: I. Plant morphology and RAPD marker characterization. Crop Science, v.41, p.552$563,2001$.

WASSOM, C.E.; BARNET, F.L. Stoloniferous behavior in birdsfoot trefoil (Lotus corniculatus L.). Agronomy Journal, v.63, p.342-344, 1971

WEDDERBURN, M.E.; GWYNNE, D.C. Seasonality of rhizome and shoot production and fixation in Lotus uliginosus under upland conditions in South-West Scotland Annals of Botany, v.48, p.8-13, 1981.

WEN, L.; KALLENBACH, R.L.; WILLIAMS, J.E. et al. Performance of steers grazing rhizomatous and nonrhizomatous birdsfoot trefoil in pure stands and in tall fescue mixtures. Journal of Animal Science, v.80, p.1970-1976, 2002.

Recebido: 29/1/2007 Aprovado: 5/7/2007 